\title{
A LOUCURA COMO QUESTÃO SEMÂNTICA: UMA INTERPRETAÇÃO KANTIANA ${ }^{1}$
}

Daniel Omar PEREZ ${ }^{2}$

- RESUMO: Apesar das mudanças do projeto kantiano, é possível identificar o problema da loucura como sendo abordado em duas perspectivas: uma fisiológica, outra semântica. A abordagem fisiológica corresponde ao modelo das ciências dos objetos dos sentidos externos. Já a abordagem semântica da loucura se desenvolve dentro da tarefa crítica da filosofia, isto é, como parte de uma investigação acerca do alcance e dos limites da razão humana. Nesse sentido, a loucura se insere em duas séries diferentes. No primeiro caso aparece vinculada às lesões cerebrais, problemas de percepção ou até mesmo em relação ao consumo de substâncias que alteram o funcionamento físico. No segundo caso se relaciona com o entusiasmo do desvario profético, o fanatismo religioso, o misticismo e até mesmo a ilusão metafísica. Para desenvolver o nosso trabalho apresentaremos elementos da abordagem fisiológica e da abordagem semântica encontradas em alguns dos diferentes textos e, por último, realizaremos algumas considerações sobre a possibilidade do desenvolvimento de um saber sobre a loucura em Kant.

- PALAVRAS-CHAVE: loucura; linguagem; fisiologia; psicologia; Kant.

1 Este artigo faz parte de uma pesquisa intitulada Antropología pragmática e filosofia prática em Kant desenvolvida com o apoio da bolsa de pesquisador do programa de produtividade em pesquisa do Cnpq-Brasil. O trabalho foi apresentado parcialmente no X Colóquio Kant da Sociedade Kant, Seção Campinas, em maio de 2008, na Unicamp.

2 Professor do Departamento de Filosofia da Pontifícia Universidade Católica (PUC) do Paraná. Pesquisador Cnpq. 


\section{Introdução}

Embora Kant ${ }^{3}$ nunca tenha desenvolvido sistematicamente os princípios de uma psicologia científica ${ }^{4}$ nem por isso deixou de tratar a questão da loucura em diferentes momentos da sua obra. Apesar das mudanças do projeto kantiano é possível identificar o problema como sendo abordado em duas perspectivas divergentes: uma fisiológica, outra semântica. A abordagem fisiológica corresponde ao modelo kantiano das ciências dos objetos dos sentidos externos (isto é, objetos possíveis de serem dados ou construídos na sensibilidade). Já a abordagem semântica da loucura se desenvolve dentro da tarefa crítica da filosofia (mesmo antes da formulação da pergunta fundamental da filosofia transcendental), isto é, como parte de uma investigação acerca do alcance e dos limites da razão humana. Nesse sentido, a loucura se insere em duas séries diferentes. No primeiro caso, aparece vinculada às lesões cerebrais, problemas de percepção ou até mesmo em relação com o consumo de substâncias que alteram o funcionamento físico. No segundo caso, relaciona-se com o entusiasmo do desvario profético, o fanatismo religioso, o misticismo e até mesmo a ilusão metafísica. As marcas dessas elaborações são encontradas em Ensaio das enfermidades da cabeça (1764), Sonhos de um visionário explicados pelos sonhos da metafísica (1766), Crítica da razão pura (1781), Crítica da razão prática (1788), A religião nos limites da mera razão (1793), Conflito das faculdades (1798) e Antropologia em sentido pragmático (1798).

Para desenvolver o nosso trabalho apresentaremos elementos da abordagem fisiológica e da abordagem semântica encontrados em alguns dos diferentes textos e, por último, realizaremos algumas considerações sobre a possibilidade do desenvolvimento de um saber a respeito da loucura em Kant no âmbito da antropologia em sentido pragmático e da medicina.

3 As citações das obras de Kant serão feitas de acordo com a paginação estabelecida na edição Kants Gesammelte Schriften /hrsg. von der Berlin-Brandenburgischen Akademie der Wissenschaften. Berlin: de Gruyter, 1902-1997.Colocaremos o nome da obra em portguês ou a sigla CRP para a primeira crítica e CRPr para a segunda crítica mais a página).

4 Kant menciona explicitamente a impossibilidade de uma psicologia como ciência empírica em Princípios metafísicos da ciência da natureza (1786). Cito: "A psicologia empírica está ainda mais longe que a química no ranking de uma ciência da natureza em sentido próprio, fundamentalmente porque as matemáticas não podem ser aplicadas aos fenômenos do sentido interno [...]" (Kant, 1786 A X) "Essa psicologia jamais poderá ser outra coisa que uma teoria histórica do sentido interno e tão sistemática quanto lhe seja possível, quer dizer, uma descrição natural da alma, porém não uma ciência da alma nem uma teoria psicológica experimental [...]" (Kant, 1786 AXI). Apesar dessas contundentes afirmações são freqüentes as pesquisas sobre a possibilidade de uma sistematização e um lugar para o conhecimento psicológico em Kant e as suas perspectivas são divergentes. Para um estudo sobre a possibilidade da psicologia em Kant em diferentes linhas ver FULGENCIO, L. (2006), BORGES, M. A. (2003), LOPARIC (2003a) (2003b), TEO, Th. (2005), HATFIELD, G. (1992) (1998), GOMES, A. (2005) e MECACCI, L. (2004). 


\section{A fisiologia da loucura e a sociedade como origem e campo para o desenvolvimento do problema}

Por um lado, Immanuel Kant é um herdeiro da tradição filosófica leibniz-wollfiana predominante na universidade da sua época, por outro lado, ele se encontra parado no umbral da modernidade científica e em contato com as descobertas da medicina e da antropologia. É nesta situação, privilegiada e incômoda, que devemos compreender as reflexões kantianas sobre a loucura, reflexões que provavelmente tenham vindo de inquietações próprias devido à sua formação ou seu projeto de tratar sistematicamente o conhecimento desde uma perspectiva de reformulação da metafísica e da ciência na sua totalidade. Mas também seria possível encontrar os traços da problemática na leitura dos sensualistas ingleses preocupados com o tema como Shaftesbury e Hutcheson, na sua interlocução com médicos como Ufeland e na sua disputa com antropólogos como Georg Forster. Anthony Ashley Cooper, 3 Lord de Shaftesbury, escreveu Characteristics of Men, Manners, Opinions, Times, publicado em 1711, trata-se de um trabalho onde encontramos uma abordagem da loucura a partir das paixões e das sensações envolvidas nos julgamentos morais. A ética de Shaftesbury estava diretamente ligada aos afetos e aos sentimentos e suas idéias são citadas em vários momentos da obra kantiana, nas publicações e nas lições de filosofia prática. Francis Hutcheson foi uma grande influência para Kant, fundamentalmente na década de 1760, quando procurava um sentimento que ligasse o princípio moral com uma referência. Kant cita explicitamente esta questão em Investigação sobre a evidência dos princípios da teologia natural e da moral (1764). Com relação a Ufeland, Kant comenta um livro da sua autoria (enviado por ele mesmo) intitulado $D a$ arte de prolongar a vida humana (1796) em O conflito das faculdades (1798), como veremos mais adiante. E em relação a Georg Forster, Kant questionou explicitamente em artigos e em suas aulas a noção de raça elaborada pelo etnologista e naturalista alemão. As viagens de Forster pelo mundo no barco do Capitan James Cook entre 1768 e 1775, lhe permitiram colher uma grande quantidade de dados e informações a partir dos quais fez uma história natural.

Na segunda metade do século XVIII a loucura estava sendo recategorizada com a ajuda das novas teorias. É na Inglaterra onde apareceu pela primeira vez o termo neurose elaborado por William Cullen em 1763 para se referir aos mais variados transtornos mentais. Nessa época a "loucura" deixa parcialmente de ser um problema da alma e, por tanto, tema de moralistas, padres e exorcistas, para começar a ser um problema dos sentidos: básicamente de sensação e imaginação. A virada colocava a tarefa de dar um tratamento racional às mudanças de humor, às alterações dos sentidos e à somatização nas pessoas "nervosas". No Tratado médico filosófico sobre a 
alienação mental ou a mania publicado em 1801 por Pinel (2007) afirma-se que a loucura se divide em: melancolia simples (delírio parcial), mania (delírio generalizado com agitação), demência (enfraquecimento intelectual generalizado) e idiotia (perturbação total das funções intelectuais). Sendo as suas causas: físicas (diretamente cerebrais ou simpáticas), hereditárias e morais que, por sua vez, podem ser: 1 - paixões intensas e fortemente contrariadas ou prolongadas e 2 - excessos de todo tipo. Mesmo assim, as hipóteses mais populares na época sobre a origem da loucura eram ainda a da teoria humoral e a dos problemas gástricos. Em Ensaio das doenças da cabeça Kant cita uma publicação da época chamada Der Arzt, nos números 150, 151 e 152. Nesses volumes o doutor Johan August Unzer publicou artigos sobre o tema da loucura e a digestão. Unzer escreveu a respeito da conexão entre entendimento e digestão afirmando que toda classe de desvarios e alguns delírios veementes podem ser curados melhorando a relação com os alimentos e o processo digestivo. Segundo Unzer a causa próxima das enfermidades dos nervos seria o cérebro, mas a causa última estaria no ventre.

No caso de Kant, encontramos vários modos de entender as origens das "doenças da cabeça", nos que se combinam questões físicas, sociais e morais, porém todas as explicações se pautam nos mecanismos da razão, onde conceitos e imaginação cumprem um papel fundamental. Em última análise, a loucura para Kant seria uma espécie de desorganização do funcionamento do mecanismo da razão, um incorreto funcionamento do julgamento sobre as sensações e as percepções. Nesse sentido, é preciso dizer que para Kant não há uma fronteira decisiva entre as loucuras mais leves e várias das condutas cotidianas dos homens comuns. O problema do julgamento sobre a matéria sensível é muito mais corriqueiro do que poderíamos imaginar. O "desvario" ou o julgamento desvairado aparece nos modos mais habituais da nossa vida e não é evidente o estabelecimento do limite exato entre o que se poderia chamar de normalidade e de loucura. Com a classificação dos muitos casos kantianos encontrados em textos publicados, fragmentos, reflexões e cartas poderíamos constituir uma verdadeira psicopatologia da vida cotidiana.

\section{Loucura no entendimento e na debilidade da vontade}

No Ensaio das doenças da cabeça encontramos uma classificação e uma compreensão causal do fenômeno da loucura, desde a paralisia, idiotia (Blödsinnigkeit) ou imbecilidade até as convulsões ou loucura furiosa. Para poder compreender sua fundamentação e justificativa apresentaremos alguns casos paradigmáticos. 
A falta de engenho, diz Kant, na capacidade de captar ou lembrar algum dado pode ser considerada como estupidez (Dummheit). Um sujeito estúpido (dumm) é alguém que padece de modo de "enfraquecimento do entendimento". O mecanismo do juízo não estaria funcionando corretamente. Porém, não devemos confundir, as habilidades podem estar mais focadas para um tipo de trabalho e negligenciadas para outro. Alguém pode ter mais gênio nas matemáticas e menos nas letras ou mais nos julgamentos especulativos e menos nos julgamentos pragmáticos ou vice-versa. A falta de entendimento também pode ser confundida com a ingenuidade quando um homem honesto e de boa vontade não faz parte das armadilhas da sociedade, a não ser como vítima. Neste caso, não nos encontramos diante de um doente, mas de uma boa pessoa que a sociedade, no seu processo de banalização das virtudes, trataria como imbecil.

Outro exemplo kantiano encontramos nas paixões que, como impulsos da natureza humana, também podem tornar o indivíduo um insensato. Neste caso, tratar-se-ia de uma espécie de "debilidade da vontade". O sujeito pode ter um bom julgamento sobre a matéria sensível que se apresenta na forma dos acontecimentos e das próprias ações, porém ele próprio não consegue realizar o que predica. Muitas vezes o indivíduo sabe que o que está fazendo não é o correto ou não é o que ele realmente quer, mas uma força maior não lhe permite governar suas ações. "A paixão amorosa - diz Kant ou uma grande ambição tem convertido desde sempre muita gente razoável em insensatos" (Ensaio sobre as doenças da cabeça, A 17). Para dar exemplo da insensatez por causa de uma paixão amorosa Kant resgata uma cena da literatura grega: o terrível Alcides obrigado por uma moça a fazer fios, uma atividade considerada feminina. Também a inclinação pelos livros, pelos quadros ou outros objetos pode levar à insensatez. O colecionador compulsivo pode ser visto como um dos modos do insensato. Trata-se daquelas pessoas que se perdem detrás do objeto desejado.

O oposto do insensato (Thor) é o sábio - diz Kant - que não devemos confundir com o apático imbecil com aparência de sábio. Quem aparenta ser sábio tenta posar de apático grego, como se estivesse para além do bem e do mal, com isso evita cair na insensatez, mas não é outra coisa que uma das formas da idiotice ou "enfraquecimento do entendimento".

Outra fonte de loucura pode ser o orgulho (Hochmuth) e a avareza (Geiz). O orgulhoso sente desprezo pelos outros e se torna tão arrogante que já não pode mais conviver com ninguém. Entretanto, esse desprezo pelos outros, longe de revelar indiferença, mostra a preocupação que o sujeito tem em relação ao julgamento dos outros. No caso do avarento encontramos uma espécie de paradoxo: um sujeito que necessita tanto das coisas que já não se pode privar de nada, mas acaba se privando de tudo. O mecanismo de base está pautado em uma "debilidade da vontade". 
Outro grupo de doenças está constituído pela alucinação (Verrückung), o delírio (Wahnsinn) e a mania (Wahnwitz). A alucinação é uma inversão nas noções da experiência sensível, o delírio é uma desordem da capacidade de julgar sobre a realidade (em ambos os casos encontramos os diferentes tipos de fantasia) e a mania é um extravio em supostas sutilezas sobre conceitos gerais. Segundo Kant, a faculdade poética criadora inscreve imagens na sensação que muitas vezes não vemos realmente. Isto pode acontecer por associação (quando uma coisa nos relembra outra), por algum tipo de paixão (como o medo que nos faz ver monstros nas sombras) ou quando completamos uma imagem que está oculta detrás de um objeto (por exemplo, o desenho de um tapete interrompido por uma parte do sofá). Não só na vigília encontramos esses fenômenos, também nos sonhos temos por real aquilo que apenas são sensações produzidas pela imaginação. Na vida cotidiana a fantasia funciona permanentemente, mas esses mecanismos podem levar à loucura quando o indivíduo não consegue distinguir mediante o julgamento a ilusão da experiência real. Porém, mesmo quando diferenciamos a sensação real da ilusória e insistimos na ilusão o fenômeno que encontramos é o do auto-engano. Trata-se daquele que quer ver aquilo que realmente não vê, como a imagem de uma santa numa pedra ou numa mancha de umidade. Outras formas de auto-engano aparecem também na vida cotidiana como na relação que às vezes temos com os excessos de comida ou bebida e queremos perceber menos quantidades das que realmente percebemos. No texto das doenças da cabeça o auto-engano parece estar associado a uma espécie de defesa contra a própria realidade, mas nas lições de antropologia o mesmo fenômeno se manifesta no âmbito de um julgamento moral, mesmo assim, nos dois casos não se trata apenas de um enfraquecimento do entendimento ou de um problema fisiológico da imaginação, parece tratar-se de uma "debilidade da vontade" diante da interpelação da realidade ou dos deveres.

Um último exemplo da "debilidade da vontade" é dado nos casos do desespero e da veemência desenfreada que podem conduzir a uma loucura furiosa e até produzir convulsões. Em uma situação de desespero o individuo pode chegar a alterar suas funções fisiológicas. O funcionamento orgânico é determinado pelo funcionamento da vontade, mas "involuntariamente". Aqui Kant nos adverte sobre idéias que podem provocar disfunções físicas. O espírito, de algum modo, altera o físico do mesmo modo que o ambiente físico ou cultural intervém no entendimento e na imaginação.

\section{Loucura como excesso de sociedade}

Seguindo as idéias de Rousseau em Emilio, Discurso sobre a origem e fundamento da desigualdade e $O$ contrato social, Kant também era partidá- 
rio da hipótese que sustenta que o desenvolvimento da sociedade e o aparecimento das doenças mentais são paralelos. No Discurso sobre a desigualdade Rousseau afirma que no estado de natureza o homem não sente necessidade de remédios nem de médicos e que quando abandona a natureza "tornando-se sociável e escravo, torna-se fraco, medroso e subserviente, e sua maneira de viver, frouxa e afeminada, acaba por debilitar ao mesmo tempo sua força e sua coragem" (Rousseau, 1999, vol. 2, p. 62). Numa linha de reflexão semelhante, no Ensaio das doenças da cabeça Kant afirma que o homem no estado de natureza poucas vezes pode ter insensatez e muito dificilmente chegará à loucura. A necessidade biológica deixa o homem próximo da experiência e isto lhe serve como seguro para um moderado uso da imaginação. Sem a preocupação pelo julgamento dos outros, sem a necessidade de aparentar aquilo que não é, o homem fica protegido da demência. Assim, a vida em sociedade e inclusive a desigualdade são para Kant fonte de males, doenças e vícios, e também da civilização e da cultura (Ver também Kant, I. [1786] Suposto começo da história da humanidade). "A coação artificial - escreve Kant - e a abundância da organização civil (da sociedade) possibilitam a aparição de homens engenhosos e razoáveis, porém, em ocasiões aparecem loucos e trapaceiros" (Ensaio sobre as doenças da cabeça. A 14). A aparição de valores na mesma medida em que propiciam o progresso fomenta também a cobiça, a inveja, a avareza e a corrupção da imaginação. Poderíamos dizer que, para Kant, o excesso de cultura produz a loucura da sociedade contemporânea, como se fosse um tipo de desvario próprio do relacionamento entre os indivíduos. Para poder justificar essas conclusões Kant utilizou um procedimento metodológico pautado em observações empíricas combinadas com considerações de caráter moral e explicações sobre o equívoco nos modos de relacionar representações intelectuais com percepções. É algo semelhante ao procedimento utilizado também nas lições de Antropologia, que começaram em 1773 e foram até 1796.

\section{Loucura no fanatismo}

Constata-se também um "desvario" bastante particular em alguns modos de compreender algumas idéias que produzem determinados tipos de discursos, a saber: o metafísico, o místico, o fanático político ou religioso. Em todos esses casos tratar-se-ia de "desvairados", quer dizer, sujeitos que utilizam conceitos sem qualquer significado efetivo e se referem a "objetos imaginários" como se fossem reais. Nesse sentido, há uma distinção muito particular feita por Kant ainda no Ensaio das doenças da cabeça entre entusiasmo (Enthusiasm) e fanatismo. O entusiasmado é alguém que tem uma grande produção de fantasia por meio da sua imaginação, mas possui 
bons sentimentos morais. Essas fantasias estimulam o sujeito e impulsionam seu agir numa determinada direção. O fanático (Fanatiker) ou o exaltado (Schwärmer) conduzem o entusiasmo a situações extremas e de iminente perigo (Ensaio sobre as doenças da cabeça, A 25-26). É o caso de políticos e religiosos fanáticos. Nesses casos, segundo Kant, não haveria "bons sentimentos".

Uma elaboração bastante exaustiva do fanatismo encontramos em 1766, no texto Sonhos de um visionário... O teósofo escandinavo Emmanuel Swedenborg declarava ter contato com espíritos que explicariam para ele como entender determinadas passagens do texto bíblico. Existe uma biografia de Swedenborg escrita por G. L. Trobridge intitulada Swedenborg, vida e ensinamentos, publicada na sua primeira edição em 1907 e traduzida para o português por Raimundo Araujo Castro Neto. A leitura do texto nos auxilia na hora de procurar uma compreensão abrangente do trabalho do científico, filósofo e teósofo escandinavo. Aparentemente Swedenborg teria relatos precisos de como seria a vida do espírito depois da morte do corpo. Em uma resenha crítica Jorge Luis Borges (1996) destaca a formação intelectual, a vitalidade e o talento literário de Swedenborg, além, é claro, da sua posição de místico. Escreve Borges:

El hecho cardinal de su vida ocurrió en Londres, en una de las noches de 1745. Swedenborg mismo lo ha denominado el grado discreto o grado de separación. Lo precedieron sueños, plegarias, períodos de incertidumbre y de ayuno, y lo que es harto más singular, de aplicada labor científica y filosófica. Un desconocido que silenciosamente lo había seguido por las calles de Londres y de cuyo aspecto nada sabemos, apareció de pronto en su cuarto y le dijo que era el Señor. Directamente le encomendó la misión de revelar a los hombres, ahora sumidos en el ateísmo, en el error y en el pecado, la verdadera y perdida fe de Jesús. Le anunció que su espíritu recorrería cielos e infiernos y que podría conversar con los muertos, con los demonios y con los ángeles. (Borges, 1996, p. 144)

A admiração de Borges por Swedenborg estava motivada na rica imaginação do escandinavo e na sua possibilidade e empenho em criar mundos tão fantásticos. É justamente pelo desvario que Swedenborg, de acordo com Borges, pertenceria à série de escritores de ficção como Leibniz, Spinoza, Berkeley e tantos outros que exercitariam a escrita da filosofia como ramo da literatura fantástica.

Embora Kant tenha comprado os livros de Swedenborg (tanto quanto os de Leibniz) e, aparentemente, lido com bastante interesse seus relatos no início, a sua posição filosófica não lhe permitiria manter alguma aproximação por muito tempo. De acordo com Kant, esse tipo de casos revela ou um problema fisiológico na percepção ou um problema semântico em relação ao uso dos conceitos. O desvairado estaria confundindo imagens ilusó- 
rias com reais ou palavras com coisas. Uma escrita que sustentasse o conhecimento para além dos objetos físicos seria em Kant, no mínimo, problemática. O "contato com espíritos", que lhe proporcionaria acesso a um mundo não-físico, apresentaria um paradoxo ou uma contradição em termos. A relação entre o material e o imaterial não se daria pela execução de um passo numa seqüência, mas por um salto num abismo. A palavra espírito como algo imaterial jamais poderia referir um objeto do nosso conhecimento que, por definição, seria necessariamente material. Mas para compreender melhor esse fenômeno é preciso entrar no texto kantiano.

\section{A semântica do espírito e da loucura}

A obra que estimula o ensaio kantiano de 1766 é um tratado místicoreligioso escrito por Swedenborg. O texto relata questões acerca do oculto, das aparições e da relação com os espíritos separados dos corpos. O escrito em questão é Arcana Caelestina, qua in Scripta Sacra seu Verbo Domini sunt detecta. Uma cum mirabilibus, quae visa sunt in mundo spiritum et in caelo angelorum pulicado entre 1749 e 1756. Os cinco primeiros volumes estudam o Gênese e os três seguintes o Êxodo. O trabalho se sustenta na leitura dos textos em língua original e no auxílio dos espíritos. A leitura kantiana começa levando a sério a proposta mística e tenta abordar racionalmente o conceito de espírito.

Entre as várias leituras existentes do texto kantiano podemos destacar o trabalho de Alison Laywine (1993) que sugere que Sonhos... é um empreendimento contra o próprio labor que Kant tinha desenvolvido nos anos de 1750. Aquela reflexão sobre os limites entre o misticismo e a racionalidade teria estabelecido um verdadeiro ponto de ruptura na obra do filósofo que lhe teria permitido passar para a Dissertatio (1770). Segundo Laywine, a única diferença entre Kant e Swedenborg seria que nos anos 1750 Kant postularia um sistema de interação real entre dois mundos, enquanto que Swedenborg teria proposto uma harmonia pré-estabelecida, mas ambos tratariam de coisas imateriais que poderiam ser acessíveis à sensibilidade humana (Laywine, 1993, pp. 8). De acordo com Laywine, no sistema de Swedenborg aquilo que predomina no céu seria uma ordem pré-estabelecida, com anjos que substituem mônadas, representada numa imagem de natureza material. "Swedenborg tem descrições detalhadas dos jardins, da vida animal e das construções no céu, bem como dos anjos, suas roupas e seus costumes. O relato de Swedenborg sobre o céu poderia ser o de uma esquina das ruas de Estocolmo" (Laywine, 1993, pp. 7-8). Assim, Kant teria descoberto nessa imagem a perfeita caricatura de sua própria metafísica. 
Podemos citar também o trabalho de Monique David-Ménard (1996) que, em chave psicanalítica, apresenta o texto kantiano como fundamental para entender o trabalho crítico desenvolvido tanto na Crítica da razão pura quanto na Antropologia em sentido pragmático. A autora afirma que:

o debate de Kant com Swedenborg, isto é, com o exemplo de um pensamento louco, é um dos temas essenciais que organizam a Crítica da razão pura. O prefácio à primeira edição dessa obra retoma, com efeito, textualmente, as críticas que em 1766 se dirigiam indistintamente ao delírio e às construções idealistas, voltando-as, no entanto apenas contra a metafísica. É na relação com essa recusa simultânea do dogmatismo e da extravagância que a própria idéia de redefinir a filosofia como ciência dos limites da razão humana, ou seja, como filosofia crítica, adquire sentido. Não foi portanto Hume quem despertou Kant do seu sonho dogmático. (David-Ménard, 1996, pp. 9-10)

Ambas as comentadoras, com linhas de abordagens e com percursos e recortes de textos diferentes, mostram a articulação entre o tema da loucura, a ruptura do empreendimento metafísico e a virada do projeto crítico de Kant. Assim sendo, ambas fornecem elementos para derrubar qualquer tentativa que procure tratar a loucura como um tópico marginal ou ocasional na obra kantiana.

Além da importância histórica e exegética o texto se revela estruturalmente sugestivo. Sonhos... permite a Kant avançar em uma crítica generalizada contra os que ele denomina de "sonhadores dos sentidos", que são aqueles que acham ter visões místicas, e também contra os "sonhadores da razão", que são aqueles que acham poder conhecer objetivamente para além da experiência sensível. Assim, a crítica dos sonhos tem duas partes, uma semântica, que trata das significações (os sonhadores da razão), e outra empírica, que trata das perturbações físicas e das doenças mentais (os sonhadores dos sentidos). A primeira parte Kant denomina "dogmática", a segunda "histórica". Partilhamos com Michele Jalley-Crampe (1979) a nomenclatura usada. No seu trabalho utiliza a noção de "semântica" para se referir à tarefa de Kant em 1766 no que diz respeito à parte "dogmática".

Assim, na primeira parte, (dogmática ou semântica) Kant formula a pergunta pela significação do conceito de espírito (der Geist) a partir de um problema concreto da filosofia: o princípio de vida. Kant reconhece estar realmente inclinado a pensar que é possível afirmar a existência de naturezas imateriais no mundo e incluir a própria alma nessa classe de seres. Isto porque aquilo que contém um princípio de vida parece ser de natureza imaterial. No entanto, uma tal afirmação nos colocaria o misterioso problema da união entre um espírito e um corpo. "Como poderia uma substância imaterial cruzar no caminho de uma matéria de modo que no seu movimento se encontre com um espírito?" (Sonhos de um visionário, p. A 25-26). Explici- 
tamente e sem qualquer ambigüidade Kant interroga: $O$ que é aquilo que o conceito de espírito enuncia? Para nos aproximar de qualquer definição o artigo kantiano indica a possibilidade de podermos dizer que um espírito parece ser uma entidade não material que possui razão. Embora seja difícil de compreender à primeira vista algo não material que possui algum mecanismo de compreensão, Kant assume a tarefa de esclarecer. "Para entender esse oculto significado -diz Kant- tomo meu mal compreendido conceito em todos seus usos e, observando a quais convém e em quais é rejeitável, espero revelar seu sentido escondido" (Sonhos de um visionário, p. A 9). O procedimento kantiano pode ser formulado do seguinte modo: para cada conceito se trata de achar o significado pelo uso em diferentes proposições que pertencem a distintos tipos de discurso. No desenvolvimento desse trabalho, Kant faz uma citação de rodapé que esclarece e delimita os procedimentos que são considerados para realizar a tarefa. Kant escreve:

Se o conceito de espírito fosse abstraído dos nossos conceitos de experiência, então o procedimento para esclarecê-lo resultaria fácil, só teria que enunciar em tal gênero de seres aqueles caracteres que nele mostram os sentidos e mediante os quais os diferenciamos das coisas materiais. Mas se fala de espíritos ainda quando se duvida de que existam tais seres. Portanto, o conceito de natureza espiritual não pode ser considerado como abstraído da experiência (...) "muitos conceitos surgem de ocultas e obscuras inferências, por causa de experiências, e se transferem depois a outras sem consciência da experiência ela mesma nem da inferência que a partir da qual se elaborou". (...) "assim existem muitos conceitos que, em parte, não são mais que uma ilusão da imaginação, e, em parte, são também verdadeiros, pois as inferências obscuras nem sempre resultam equívocas. A linguagem usual e a conexão de uma expressão com diferentes contextos nos quais freqüentemente encontra-se uma mesma característica fundamental outorgam-lhe um significado determinado que, em conseqüência, só pode ser desvelado se tirarmos da escuridão esse sentido oculto mediante uma comparação com todos os usos que concordem com ele ou que o contradigam. (Sonhos de um visionário, p. A 9-10)

Esse procedimento, desenvolvido em Sonhos... já tinha sido enunciado no texto de 1763 quando tratara da diferença entre os conceitos da matemática e da metafísica. Como podemos observar, a questão não é rejeitar sem argumentos o conceito de espírito, nem fornecer uma definição vazia sem qualquer referência objetiva. Na primeira parte da citação, Kant explica o procedimento dos conceitos empíricos obtidos pela abstração de notas características que nos fornecem os sentidos, na segunda parte trata da transferência dos conceitos para outros contextos de uso. Esse último é o procedimento utilizado por Kant no corpo do texto de 1766. Conduzido basicamente por meio da oposição às propriedades da matéria, fundamentalmente a da impenetrabilidade, chega a uma definição de "espíritos", a saber: 
[espíritos são] seres que não possuem em si mesmos a propriedade de impenetrabilidade e que nunca poderão formar um todo sólido (...) Os seres simples dessa classe se chamam de imateriais, e, se possuem razão, espíritos.... (e afirma ainda...). Ou o nome de espírito é uma palavra sem sentido ou seu significado é esse. (Sonhos de um visionário, pp. A 12-13)

Em qualquer situação, a definição proposta não nos permite garantir a realidade objetiva do conceito em questão, como poderia ser o caso da definição de círculo que é a própria regra para construir o objeto círculo. Isto é, dado um ponto e uma série de pontos que formam um segmento que gira em torno do primeiro ponto obtenho um círculo. Assim, poderíamos ter conceitos empíricos obtidos por abstração de notas características extraídos de objetos da percepção ou conceitos matemáticos ou geométricos que nos permitem construir o objeto ao qual se referem. No caso do "espírito" tratase apenas de um conceito sem possibilidade de objeto ao qual se referir.

Com efeito, diz Kant, geralmente se considera que é possível captar a possibilidade daquilo que pertence aos conceitos comuns de experiência. Pelo contrário, do que se afasta deles e não pode se fazer compreensível por meio de experiência alguma, nem mesmo por analogia, disto realmente não pode se formar nenhum conceito, razão pela qual se costuma rejeitá-lo como impossível. (Sonhos de um visionário, p. A 14)

Kant faz aqui uma distinção decisiva entre conceitos possíveis, isto é, aqueles que têm seu referente na experiência e, conceitos impossíveis, ou seja, aqueles conceitos cujo objeto de modo nenhum se dá na experiência e são contraditórios. No texto crítico Kant manterá a questão da referência embora mude a hierarquia das classes de conceitos. Isso possibilitará salvar o estatuto de conceito de objetos "impossíveis" que é utilizado corretamente para a explicação de uma experiência. Assim, Kant nos explica que o conceito de força, embora seja pertinente à experiência, não nos permite compreender a possibilidade daquele por meio da apresentação de um objeto. "Através da experiência - diz Kant - só pode se descobrir que as coisas do mundo que chamamos de materiais têm tal força, mas nunca compreender sua possibilidade" (Sonhos de um visionário, p. A 15). É impossível conhecer objetivamente a natureza de uma força, mais ainda, poderíamos dizer que se trata de uma questão sem sentido. Isso se torna mais claro quando pensamos no conceito de força gravitacional à distância, que na física moderna nos permite explicar a regularidade do movimento dos planetas do sistema solar. O conceito de força mesmo que sem objeto, permitenos pensar uma atividade das nossas representações empíricas e graças a esse conceito podemos prever com exatidão eclipses e mudanças na maré.

O conceito em questão operaria no interior de uma experiência matematizada. Contudo, o mesmo não acontece com o conceito de espírito, já 
que surge a impossibilidade de pensá-lo neste sentido e de que funcione como os construtos físico-matemáticos. Embora devamos dizer também que não se trata de uma impossibilidade provada, “...pode se supor a possibilidade de seres imateriais sem temor de ser refutado" - escreve Kant, mas também acrescenta - "e sem esperança de poder demonstrar essa possibilidade mediante argumentos racionais" (Sonhos de um visionário, p. A 16).

Continuando com seu trabalho, Kant tenta achar uma significação possível da noção de espírito associada com o conceito de "princípio de vida", e mais tarde busca aplicar o conceito às ações morais. Em nenhum dos dois casos pode ser sustentada uma significação de espírito como conceito referido a objeto como entidade separada. Da mesma forma como aconteceu anteriormente, também aqui se provará a impossibilidade do conceito, razão pela qual já sem poder dar uma clara significação, Kant nos adverte que: assim como existem "sonhadores da razão" que fantasiam em vez de observar, existem também "sonhadores da sensação" e são aqueles que têm trato com os espíritos (Sonhos de um visionário, p. A 59-60 e ss).

Devido a isso, Kant recorre agora a explicar o acontecimento como um fenômeno da imaginação ou algum tipo de perturbação no cérebro ou no sistema nervoso da vista. Com efeito, a explicação de um conceito só pode se dar através da elucidação do seu significado, inclusive em diferentes campos ou usos (a saber, teológico, religioso, científico, ético, etc.) ou em termos médico-psiquiátricos (quer dizer, como uma disfunção no funcionamento da natureza). Assim sendo, o trato com os espíritos só pode ser explicado racionalmente dessas duas maneiras. Isto é, como uma confusão semântica ou como uma perturbação física. O que conduz à conclusão de não mais aceitar a proposta de um conceito de espírito separado do corpo no registro das explicações causais da experiência. A única legitimação possível das "histórias sobre aparições das almas separadas ou sobre influxos de espíritos e todas essas teorias sobre a natureza provável dos seres espirituais e sua relação conosco é só a esperança diante da morte". Esse "esperar" não explica nada teórica e objetivamente, embora (segundo o Kant de 1766) não possa ser rejeitado por ciência alguma. No final deste mesmo ensaio Kant faz uma paráfrase do texto de Voltaire na personagem de Cândido e convida-nos a "cuidar da nossa felicidade e a cultivar o nosso jardim" (Sonhos de um visionário, p. A 128), advertindo que sobre esse tipo de questões só pode-se opinar, mas nunca saber algo positivamente a seu respeito. No caso contrário estaremos construindo mundos ilusórios e metafísicos. Swedenborg, Leibniz e inclusive o próprio Kant dos anos 1750 teriam transitado, como o personagem de Cervantes no Quixote, pelas fantasmagorias das lutas contra gigantes e campos de batalhas sem perceber que eram moinhos de vento e lavouras. Como em um espelho Kant teria visto 
sua própria imagem em Swedenborg. Em 1766 a própria mensagem de Kant lhe retorna em forma invertida. O que teria sido para Kant um grande projeto de reformulação da metafísica, tal como confessa em várias cartas a Lambert, se lhe apresenta como um discurso desvairado e o resultado disso é um interrogante: será que antes de reformular toda a metafísica não é necessário perguntar pela sua própria possibilidade? O tratamento da loucura como desvario nos coloca diante da metafísica como discurso desvairado.

\section{Do desvario místico de Swedenborg ao desvario metafísico na ultrapassagem dos limites da razão na primeira crítica}

O ponto central do trabalho sobre Swedenborg está menos em uma crítica ao misticismo do que ao perigo do desvario do discurso metafísico. A viagem extática de um desvairado (Schwärmers) como Swedenborg que parece ser impulsionada por uma intuição fanática (fanatischem Anschauen) e que produz visões de três classes (Sonhos de um visionário, p. A 99-100 e ss.) se aproxima demasiado aos mundos construídos por Wolff e Crusius (Sonhos de um visionário, p. A 58-59). Como Borges, Kant também reconhece certo tom fantástico na escrita metafísica. O tratamento do tema da loucura em Kant começa como um problema médico sobre questões patológicas, ${ }^{5}$ mas aos poucos vemos que o rumo se orienta para o tratamento do misticismo como um modo de fanatismo e desvario que lhe permite começar a introduzir a pergunta sobre os limites da razão na sua busca pelo desenvolvimento do conhecimento metafísico. O que mais poderia ser afinal o resultado do texto de 1766 senão a formulação da idéia de que a metafísica não mais seria a ciência dos espíritos ou de qualquer tipo de entidades do além e sim uma ciência dos limites da razão humana? (Sonhos de um visionário, p. 115-116). É com essa orientação que Kant se guia na elaboração da crítica da razão pura teórica e da prática. É nesse horizonte que são tratados os fanatismos, misticismos e as ilusões metafísicas, como desvarios de uma razão que produz discursos loucos.

\section{A crítica de uma ilusão: conhecer o impossível}

Monique David-Ménard afirma que em Kant "a problemática da limitação do conhecimento ao campo dos objetos tem a função de evitar uma lou-

5 Ver Ensaio das doenças da cabeça. 
cura (Wahn) do pensamento. Toda a semântica da loucura em sua relação com o tema crítico é exatamente a mesma em 1766 e em 1781. É esse o objeto do prefácio da primeira edição da Crítica" (David-Ménard, 1996, 117). Com efeito, a semântica kantiana dos conceitos e das proposições estabelece procedimentos de doação de sentido que permitem determinar o alcance da razão em matéria de conhecimento teórico e prático. ${ }^{6} \mathrm{Na}$ Crítica da razão pura, a investigação dos mecanismos de funcionamento da razão evita ou tem como objetivo evitar as puras quimeras da invenção de conceitos imaginários e a procura de um conhecimento acerca do impossível. 0 tom metafórico do prefácio à primeira edição da Crítica torna mais visível ainda a pesquisa do alcance e dos limites da razão como um modo de evitar o uso desvairado desta. "Para Kant, trata-se, através do trabalho da Crítica, de deixar a razão desfazer sua própria loucura, que ela ama e cultiva" (David-Ménard, 1996, 121). Cito Kant:

A razão humana, num determinado domínio dos seus conhecimentos, possui o singular destino de se ver atormentada por questões que não pode evitar, pois lhe são impostas pela sua natureza, mas às quais também não pode dar resposta por ultrapassarem completamente as suas possibilidades. (CRP, A VII)

E mais adiante:

Assim, a razão humana cai em obscuridades e contradições, que a autorizam a concluir dever ter-se apoiado em erros, ocultos algures, sem, contudo, os poder descobrir. Na verdade, os princípios de que se serve, uma vez que ultrapassam os limites de toda experiência, já não reconhecem nesta qualquer pedra de toque. O teatro destas disputas infindáveis chama-se Metafísica. (CRP, A VII)

A revolução copernicana de Kant nos obriga a observar que a ultrapassagem dos limites da razão não é algo imposto desde fora, seu próprio funcionamento pode levar a produzir o Wahn que, como David-Ménard também nota na língua francesa, nas distintas traduções para o português da Crítica aparece como presunção (CRP B514) e opinião ilusória (einem trüglichen Wahne) (CRP B525). É assim que podemos afirmar com Kant que haveria uma lógica da ilusão, da opinião ilusória, da presunção da razão para ultrapassar seus próprios limites (de acordo com seu funcionamento). É por causa desse Wahn que a razão precisa de um tribunal e de uma disciplina. O disciplinamento da razão, o corte de um funcionamento desvairado não é determinado pela escolha de um dogma de escola, mas pela crítica, isto é,

6 Para um estudo mais apurado da semântica transcendental kantiana ver LOPARIC 2000, PEREZ 2008. 
pela descrição das condições de possibilidade (validade) dos conceitos e proposições. "Só a crítica - diz Kant - pode cortar pela raíz o materialismo, o fatalismo, o ateísmo, a incredulidade dos espíritos fortes, o fanatismo e a superstição, que se podem tornar nocivos a todos e, por último, também o idealismo e o ceticismo, que são, sobretudo, perigosos para as escolas e dificilmente se propagam no público" (CRP B XXXIV). A tarefa crítica em 1781 tem um aspecto terapêutico: expurgar os dogmatismos e os ceticismos como desvarios ou discursos loucos.

\section{A crítica de um exagero: entre o empirismo moral e a devoção absoluta}

Se na primeira crítica encontramos uma ênfase dado aos cuidados de uma ultrapassagem do uso da razão teórica no Wahn metafísico, na segunda os cuidados são para com o Schwärmerei e o Fanatizismus moral e religioso. Na Crítica da razão prática o misticismo, tão combatido antes, seria menos pernicioso do que o próprio empirismo. Cito Kant:

\footnotetext{
o misticismo ainda é compatível com a pureza e sublimidade da lei moral e, além disso, não é precisamente natural e adequado à maneira de pensar comum estender a sua faculdade de imaginação até intuições supra-sensíveis, por conseguinte, deste lado o perigo não é tão geral; contrariamente, o empirismo extermina na raiz a moralidade de disposições (nas quais, porém, e não simplesmente em ações, consiste o elevado valor que a humanidade pode e deve obter para si através dela) e substitui o dever por algo completamente distinto, a saber, um interesse empírico, com o qual as inclinações em geral travam relações recíprocas e, por isso mesmo, também com todas as inclinações que (tomem elas o feito que quiserem), se são elevadas à dignidade de um princípio prático supremo, degradam a humanidade e, com elas, contudo, são tão favoráveis à índole de todos, o empirismo é por isso muito mais perigoso que toda a insânia da razão (Schwärmerei), que jamais pode constituir um estado duradouro de um grande número de seres humanos. (CRPr 125-26, grifo nosso)
}

Assim como Sonhos de um visionário e a própria Crítica da razão pura podem ser entendidos como apontando para os próprios desvarios de Kant na sua tentativa de buscar uma metafísica certa, também encontramos aqui (na segunda crítica) uma posição semelhante. O próprio Kant afirmou na primeira crítica que a moral não pertenceria à filosofia transcendental por se tratar de um problema empírico. Essa "insânia da razão" é atacada na segunda crítica como o mais perigoso dos desvarios, mais grave ainda que o Wahn dos místicos.

O outro modo de desvario a levar em conta está algumas páginas mais adiante, onde Kant afirma que é preciso impedir e se possível prevenir um 
Schwärmerei ${ }^{7}$ moral (CRPr 150). É puro Schwärmerei moral supor as ações nobres, sublimes e magnânimas, como sendo executadas por mérito, levando adiante a ilusão de que não fossem dever (CRPr 151). "Se Schwärmerei" - diz Kant - " no significado mais geral, é uma transgressão dos limites da razão humana, empreendida sobre a base de proposições fundamentais, então o Schwärmerei moral é essa transgressão dos limites que a razão pura prática estabelece para a humanidade", pelos quais proíbe pôr o fundamento determinante subjetivo de ações conformes ao dever em qualquer coisa que não seja o "respeito por essa lei" (CRPr 156). A força da lei mandando em nós como imperativa fere necessariamente o amor de si. Se algum prazer existe não está em obedecer a lei, mas ter obedecido apesar das minhas inclinações patológicas. Kant opõe este Schwärmerei à disciplina dos costumes. É preciso que o golpe contra o amor-próprio que se experimenta perante a lei moral mandando em mim como imperativa e que se transforma em respeito (Achtung) como sentimento moral a priori (CRPr 131) não acabe em um desvario Schwärmerei que substitua o fundamento do dever por algum tipo de graça ou peculiaridade da alma. O tempo da nobreza aristocrática acabou, agora se trata de cidadãos que agem conforme a lei e pela lei sem qualquer natureza que os diferencie em relação com o uso da razão prática.

\section{O discurso dos terroristas como um modo do desvario}

Quando Kant explora a tendência moral do gênero humano na história introduz o sentimento de "entusiasmo". Escreve Kant: "o verdadeiro entusiasmo refere-se sempre ao ideal e, claro está, puramente moral, o conceito de direito, por exemplo, e não pode enxertar-se no interesse próprio" (Conflito das Faculdades A 146-7). Trata-se do entusiasmo do espectador que por ocasião da revolução (francesa) se sente impulsionado a agir por dever e promover as mudanças necessárias para o desenvolvimento da República e então assinalar o progresso da história. Garrido Pimenta $(2004,288)$ marca a diferença que apareceria em várias obras de Kant entre entusiasmo como sentimento moral e Schwärmerei como uma paixão. O entusiasmo no Conflito das faculdades e na Crítica da faculdade de julgar seria uma disposição vigorosa associada a uma experiência sublime, já Schwärmerei poderia ser traduzido como exaltação. No primeiro caso teríamos um "sentimento moral" (segundo Garrido Pimenta) associado aos juízos sublimes e ao juízo da história. Porém, no segundo caso, o sentimento de exaltação por ocasião dos acontecimentos da história estaria associado com os juízos terroristas.

7 Valerio Rohden opta pela tradução "fanatismo", nós preferimos o termo "desvario". 
Segundo Kant, para o julgamento dos terroristas as coisas não poderiam estar pior e o Julgamento Final estaria à porta. Os acontecimentos seriam o signo do final dos tempos porque o afeto associado a eles é um Schwärmerei. Assim, "o Schwärmer sonha já com a restauração de todas as coisas e com um mundo renovado, após este ter perecido no fogo" (Conflito das Faculdades A 135-6). Como podemos compreender não se trata de um erro de percepção por causa de um problema no "sistema nervoso da vista", também não é um erro de cálculo por causa de um funcionamento incorreto do entendimento. Trata-se de um sentimento que acaba determinando o julgamento e impulsionando o sujeito a agir de modo exaltado. O terrorista tem um discurso louco que obedece a uma semântica precisa.

\section{Uma dieta para emagrecer o pensar e diminuir a loucura da hipocondria}

Do terrorista exaltado à morbidez melancólica encontramos em Kant a passagem do desvario na história e na política para a medicina. De acordo com Kant, no Ensaio das doenças da cabeça a hipocondria é uma ilusão que parte de uma sensação do próprio estado e parece se apoderar de todo o corpo do indivíduo até estender algo assim como um "vapor melancólico" que torna o sujeito o receptáculo de todas as enfermidades. Em ObservaÇões sobre o sentimento do belo e do sublime afirma que o homem de temperamento melancólico não se ocupa muito do julgamento dos outros, isto é, daquilo que outros consideram como bom ou como verdadeiro, seus motivos se transformam em princípios e sua convicção em obstinação, o resultado é o isolamento. O melancólico imagina-se com relação aos males da vida entrando em estados de tristeza e morbidez. É dos pensamentos mórbidos que Kant nos fala também em $O$ conflito das faculdades. Naquela oportunidade Kant dava resposta a uma carta do senhor Ufeland. O trabalho do senhor Ufeland, publicado num livro intitulado Da arte de prolongar a vi$d a$, abordava moralmente a estrutura física do homem. Quer dizer, a estrutura física do homem, segundo Ufeland, estaria ordenada de acordo com os fins morais e mostraria a cultura moral como um elemento indispensável para a perfeição física da natureza humana. Este não é o único pensador que associava, na época, o funcionamento fisiológico da natureza humana com fins morais da humanidade. Herder, seguindo as influências kantianas, já tinha elaborado uma teoria da história natural da humanidade pautada por aquela concepção. No trabalho intitulado Idéia de uma filosofia da história da humanidade (1784) Heder se esforça em relacionar o comportamento humano com os conceitos de "caráter nacional" ou "caráter do povo", "meio ambiente" e "mudanças no tempo". A racionalidade, a situação geo- 
gráfica, o clima e o tempo estariam em estreita relação com a estrutura física do homem para a realização dos fins morais. Apesar de Kant ter criticado em 1785 o trabalho de Herder, em uma resenha do livro, parece ter gostado da idéia de Ufeland em 1798 e em função disso sustentou que um bom médico não só pode ser guiado pela razão teórica, senão que deve ser guiado também pela filosofia prática, no sentido da moralidade. Assim, Kant formulava um conjunto de prescrições que permitiriam evitar o surgimento de sentimentos mórbidos, como se fosse uma espécie de pragmática médica capaz de ir além do mero conhecimento guiado pelo juízo empírico. Esta pragmática estaria apoiada no poder que o ânimo tem de ser senhor dos seus sentimentos mórbidos, utilizando apenas o simples propósito firme da razão. Kant dá o nome de "dietética" a uma série de exercícios físicos e intelectuais que constituiriam um modo de vida capaz de evitar uns sentimentos e favorecer outros. Se a terapêutica é um procedimento de cura onde o sujeito pode apenas ser passivo em relação com as intervenções do médico, na dietética kantiana se pressupõe uma atividade à qual o paciente deveria ser convidado em cada caso. O exercício de um propósito firme exige como condição a força da vontade que está afetada pelos sentimentos mórbidos e pela imaginação. Assim sendo, cada situação requereria uma prática singular, dadas as condições particulares do paciente, sem possibilidade de formular um conjunto de regras fixas que em modo nenhum poderia ser universalizado. Porém, os princípios da dietética que favoreceriam a saúde física do sujeito devem ser tirados das prescrições morais da filosofia transcendental kantiana. As obrigações para comigo mesmo e com os outros como cuidar e prolongar a própria vida, as prescrições como cuidar da saúde (física e mental), honrar a velhice (a dos outros e a própria), procurar ser o melhor possível no trabalho e nos estudos (ver Metafísica dos costumes. Doutrina da Virtude) seriam elementos da dietética contra a melancolia. Contrariamente, adotar como regra uma prescrição que afeta a saúde não só é uma imprudência desde o ponto de vista da medicina, senão uma regra que vai contra o imperativo categórico, isto é, irracional tanto no sentido teórico quanto no sentido prático. Kant, próximo do estoicismo, propõe algo como uma "medicina filosófica", um tratamento através do controle das representações intelectuais (idéias) que permita diminuir a dor e o sofrimento. Procura-se tornar consciente, mediante o uso da razão e da força da vontade, os sentimentos e os mecanismos da imaginação que levam o sujeito ao desvario melancólico. Deste modo, como diz Kant, seria possível ativar uma "força vital" que não permitiria nos entregarmos aos sentimentos mórbidos e à hipocondria.

A hipocondria não é outra coisa que um fenômeno que não tem seu fundamento no funcionamento fisiológico do corpo senão na imaginação e sua relação com o entendimento. É o caso do paciente que julga ter todas 
as doenças que aparecem nos livros de medicina e se entrega aos sentimentos de morte e desolação. É uma espécie de desvario onde se confundem idéias (e quimeras) com doenças físicas ao ponto de produzir essas mesmas doenças. Haveria um efeito que se produz no nível fisiológico, mas que tem como causa um elemento da razão. O médico que só se guia pela razão teórica, pelos julgamentos empíricos e pelas experiências não poderá ajudar o paciente nesse caso. Ele apenas poderá constatar que nada fisiológico se encontra na base desse sentimento e do desenvolvimento motivado por ele. Porém, de acordo com Kant, aquele médico que conheça a filosofia prática poderá convidar o paciente para realizar outro tipo de tratamento. Poderá levar adiante uma dietética do "jogo do seu pensamento". Com efeito, o exercício consistirá em eliminar representações desvairadas que aparecem involuntariamente, mas acabam determinando o rumo da sua vida.

A fórmula do tratamento então passará por uma "dieta do pensar". Com esta dieta o individuo poderá: 1. por em ordem suas representações, 2. distinguir juízos de sensações e 3. poder desencadear ou evitar relações causais que afetem seu corpo. Com efeito, a "dieta de idéias ou pensamentos" desencadearia relações causais físico-mecânicas com relação à força vital. Não sem surpresa, qualquer leitor de Kant que lembre o "abismo intransponível" entre o âmbito teórico e o prático, entre o fenômeno e o noumeno, advertirá que o filósofo de Königsberg está entrando em uma área muito delicada, nomeadamente, a relação entre espírito e corpo. Os exercícios espirituais (ou do intelecto) acabariam alterando a relação entre os corpos. Segundo Kant, afastando os nossos pensamentos das dores e dos sofrimentos que se apresentam na vida ou ocupando o nosso tempo cotidiano em atividades intelectuais poderemos afastar também os sentimentos mórbidos e favorecer a boa saúde física e mental. Contrariamente, quando apenas nos focamos nos sofrimentos que padecemos mergulhamos ainda mais na dor e não mais conseguimos sair dessa situação, tomados pelos sentimentos mórbidos. Esse caminho, certamente, favorece a doença e a morte. É assim, que a atividade filosófica tem também o seu papel na dieta. Filosofar - afirma Kant - sem ser por isso um filósofo profissional, é um modo de espantar sentimentos desagradáveis, produz uma agitação do ânimo que introduz um interesse na sua ocupação mental independentemente das contingências externas ao jogo. O exercício intelectual abstrato não deixa que a força vital fique parada. Por isso, Kant aconselha exercícios de matemática e a leitura da filosofia transcendental (na Crítica da razão pura), que como conhecimentos puros, abstratos, forneceriam incentivos para a nossa força vital. É como se a razão pura fosse uma espécie de estimulante, como se a Crítica da razão pura fosse uma dose de um fármaco que agita o ânimo. Para um homem de letras ou para um erudito o pensamento é uma espécie 
de alimento necessário para sua vida, mas o excesso pode transformar o indivíduo em um doente (desvairado). De tanto pensar ele pode mergulhar na melancolia e no desânimo. Assim sendo, Kant adverte contra exageros: o excesso do pensamento pode ser prejudicial para a saúde, como se fosse uma espécie de overdose que pode causar insônia, agitação descontrolada, desvario, alucinação ou até mesmo convulsões. Para evitar que isso suceda Kant propõe: passeios livres e desinteressados, almoços e jantares sem leitura de livros, conversas lúdicas onde a reflexão apurada deve estar ausente; cuidar para que o livre jogo da imaginação possa ter seu lugar na vida cotidiana exercitando na medida adequada as fantasias entre outras coisas. Isto impediria que a imaginação sem freio dirigisse o indivíduo ao Schwärmerei. Nesses casos, por conselho médico o paciente tentará expulsar seus "pensamentos mórbidos", porém, eles poderão voltar quase que irremediavelmente conduzindo a um jogo involuntário da imaginação se não se respeitar as prescrições da dieta.

\section{Conclusão}

O tratamento da loucura não pode ser considerado como se fosse um elemento marginal à temática fundamental de Kant. Está estreitamente ligado com a tarefa da filosofia crítica. Diria ainda que o desenvolvimento da própria tarefa crítica tem de ver-se com isso constantemente. Por um lado, aparece como um problema localizado no funcionamento orgânico ou fisiológico do indivíduo. Desse modo, a loucura torna-se objeto de uma ciência da natureza, que operaria no nível da causalidade físico-mecánica. O problema se resolveria como se resolve qualquer problema da natureza. Por outro lado, aparece como um problema no uso da razão, quer dizer, no modo em como são aplicados os conceitos na construção de proposições e na elaboração de discursos. Assim sendo, o desvario dos diferentes dogmatismos e das variadas formas da "loucura" nos indivíduos que aparece nas formas de Wahn, Wahnsinn, Schwärmerei, Fanatismus, Schwermut, entre outros, não podem ser tratados senão sob a modalidade de problemas semânticos. Dito sem ambigüidades: a loucura não diz "qualquer coisa", obedece a uma semântica precisa. Para abordar o problema desse modo, na perspectiva kantiana, não há propriamente uma psicologia como ciência, mas uma espécie de "pragmática" e muita crítica em sentido transcendental (semântica).

PEREZ, Daniel Omar. Madness as a semantic question: a Kantian interpretation. Trans/Form/Ação. São Paulo, v.32(1), 2009, p.95-117. 
- ABSTRACT: Despite of the changes in the kantian project is possible to identify the problem of the madness as being boarded in two perspectives: 1. physiologic, 2. semantic. The physiologic approach corresponds to the model of the sciences about objects of the external senses. The semantic approach of the madness develops inside of the critical task of the philosophy, that is, as part of an investigation concerning the reach and the limits of the human reason. In this sense, the madness is in two different series. In the first case it appears entailed to the cerebral lesions, problems of perception or with the consumption of substances that change the physical operation. In the second case it relates with enthusiasm prophetic, the religious fanaticism, mysticism and even with the metaphysic. To develop our work here will present elements of the physiologic approach and of the semantic approach found in some of the different texts and, finally, will accomplish some considerations on the development possibility of one know about the madness in Kant.

- KEYWORDS: madness; language; physiology; psychology; Kant.

\section{Referências bibliográficas}

BORGES, J. L. Emanuel Swedenborg. Mystical Works. In: Jorge Luis Borges. Obras Completas. Vol. IV. Barcelona: Emece Editores, pp.142-150, 1996.

BORGES, M. L. "Psicologia empírica, antropologia e metafísica dos costumes". Kant e-prints vol. 2, n'.1, p. 1-10, 2003.

DAVID-MÉNARD, M. A Loucura na Razão Pura. RJ: Editora 34, 1996.

FULGENCIO, L. "O lugar da psicologia empírica no sistema de Kant". Kant e-prints, Série 2, v. 1, n. 1, p. 89-118, 2006.

GARRIDO PIMENTA, P. P. "Entusiasmo e fanatismo na filosofia crítica". Discurso, 34, p. 271-94, 2004.

GOMES, A. "Uma ciência do psiquismo é possível? A psicologia empírica de Kant e a possibilidade de uma ciência do psiquismo". Revista do departamento de Psicologia - UFF, v. 17, n.1, p. 103-111, 2005.

HATFIELD, G. "Kant and the empirical psychology in the 18th Century". Psychological Science. vol. 9, n. 6, 1998.

"Empirical, rational, and transcendental psychology: Psychology as science and as philosophy". IN GUYER, P. ed. Cambridge Companion to Kant. Cambridge: Cambridge University Press, p. 200-227, 1992.

JALLEY-CRAMPE, M. "La raison et ses rêves Kant juge de Swedenborg". Revue des Sciences Humaines, Tome XLVIII, nº 176, p. 9-21, 1979.

KANT, I. Kants Gesammelte Schriften. 29 Band. Berlin: Walter De Gruyter, 1902.

. Crítica da razão pura. Lisboa: Fundação Calouste Gubelkian. Tradução Pinto dos Santos e Fradique Morujão, 1994.

Crítica da razão prática. São Paulo: Martins Fontes. Tradução Valerio Rohden, 2002. 
KANT, I. Ensayo sobre las enfermedades de la cabeza. Madrid: Mínimo tránsito. Traducción y notas Alberto Rábano Gutiérrez y Jacinto Rivera de Rosales, 2001.

O conflito das faculdades. Lisboa: Edições 70. Tradução Artur Morão, 1993.

LAYWINE, A. Kant's Early Metaphysics and the Origins of the Critical Philosophy. Vol.3. Atascadero: North American Kant Society Studies in Philosophy, 1993.

LOPARIC, Z. A Semântica Transcendental de Kant. v. 29. Campinas: Unicamp, Coleção CLE, 2000.

. "As duas metafísicas de Kant". Kant e-prints vol. 2, n. 5, p. 1-10, 2203a.

"De Kant a Freud: um roteiro". Natureza humana 5 (1), p. 231-245,2003b.

MECACCI, L. "Introduzione". IN KANT, I. Lezioni di psicologia. Roma-Bari: Editori Laterza, p. 1-29, 2004.

PEREZ, D.O. Kant Pré-Crítico. A Desventura Filosófica da Pergunta. Cascavél: Edunioeste. Brasil, 1998.

Kant e o problema da significação. Curitiba: Champagnat, 2008.

PINEL, PH. Tratado médico filosófico sobre a alienação mental ou a mania. Porto Alegre: Editora da UFRGS, 2007.

ROUSSEAU, J-J. Discurso sobre a seguinte questão proposta pela Academia de Dijon: qual é a origem da desigualdade entre os homens, e é ela autorizada pela lei natural? IN ROUSSEAU. Coleção Os Pensadores vol 1-2. São Paulo: Editora Nova Cultural, 1999.

SHAFTESBURY, Characteristics of Men, Manners, Opinions, Times. Cambridge: Cambridge University Press, 2001.

TROBRIDGE, G. L. Swedenborg, vida e ensinamentos. Rio de Janeiro: Sociedade Religiosa A Nova Jerusalém, 1998.

TEO, Th. The critique of psychology. From Kant to postcolonial theory. New York: Springer. Series Editor: Robert W. Rieber, 2005. 